\title{
The significance of lobular neoplasia on needle core biopsy of the breast
}

\author{
S. Menon • G. J. R. Porter • A. J. Evans • I. O. Ellis • \\ C. W. Elston • Z. Hodi • A. H. S. Lee
}

Received: 25 January 2008 /Revised: 28 February 2008 / Accepted: 9 March 2008 /Published online: 4 April 2008

(C) Springer-Verlag 2008

\begin{abstract}
The management of a core biopsy diagnosis of lobular neoplasia is controversial. Detailed radiologicalpathological review of 47 patients with cores showing classical lobular neoplasia was performed (patients with pleomorphic lobular carcinoma in situ (LCIS) or associated risk lesions were considered separately). Immediate surgical excision in 25 patients showed invasive carcinoma in 7 , ductal carcinoma in situ (DCIS) in 1 and pleomorphic LCIS in 1; radiological-pathological review showed that the core biopsy missed a mass in 5, missed calcification in 2 and that calcification appeared adequately sampled in 2 . Nineteen patients had follow-up of at least 2 years. Four patients developed malignancy at the site of the core biopsy (invasive carcinoma in three, DCIS in one); one carcinoma was mammographically occult, one patient had dense original mammograms and two had calcifications apparently adequately sampled by the core. In conclusion, most carcinomas identified at the site of core biopsy showing lobular neoplasia were the result of the core missing the radiological lesion, emphasising the importance of multidisciplinary review and investigation of any discordance. Some carcinomas were found after apparently adequate core biopsy, raising the question of whether excision biopsy should be considered after all core biopsy diagnoses of lobular neoplasia.
\end{abstract}

\section{G. J. R. Porter · A. J. Evans}

Department of Radiology, Nottingham University Hospital,

City Hospital Campus,

Nottingham, UK

S. Menon • I. O. Ellis · C. W. Elston · Z. Hodi • A. H. S. Lee $(\bowtie)$ Department of Histopathology, Nottingham University Hospital, City Hospital Campus, Hucknall Road,

Nottingham NG5 1PB, UK

e-mail: andrew.lee@nuh.nhs.uk
Keywords Lobular neoplasia · Atypical lobular neoplasia · Lobular carcinoma in situ · Pleomorphic lobular carcinoma in situ $\cdot$ Needle biopsy $\cdot$ Breast

\section{Introduction}

Lobular carcinoma in situ (LCIS) was described by Foot and Stewart [25]. The term atypical lobular hyperplasia (ALH) was later introduced to describe a similar lesion, but with less marked changes. We prefer the term lobular neoplasia [30], which includes both LCIS and ALH, particularly for core biopsies in which there is limited tissue, making distinction between ALH and LCIS difficult.

The relationship between lobular neoplasia and invasive carcinoma of the breast is controversial [28]. Lobular neoplasia is often multifocal and bilateral [4]. There is evidence that it is a risk factor for invasive carcinoma in both breasts: after a diagnosis of lobular neoplasia, there is an increased risk of subsequent invasive carcinoma in both breasts [30], and the majority are ductal in type. Recent evidence suggests that lobular neoplasia may, like ductal carcinoma in situ (DCIS), be a non-obligate precursor for invasive carcinoma at the same site. There is a higher risk of invasive carcinoma in the ipsilateral than in the contralateral breast. The proportion of subsequent carcinomas that are of lobular type is higher than in unselected series of carcinomas [45]. The morphology of the cells in lobular neoplasia and invasive lobular carcinoma is similar. The same truncating mutation in the E-cadherin gene has been found in invasive lobular carcinoma and adjacent LCIS [57].

The significance of lobular neoplasia in breast needle core biopsies is uncertain. Invasive carcinomas are sometimes identified after a core biopsy diagnosis of lobular 
neoplasia. Some studies suggest this occurs because the core biopsy missed the lesion and so does not explain the clinical or radiological abnormality [41]. Other studies suggest that carcinomas may be identified after the diagnosis of lobular neoplasia on core biopsy even if the core biopsy explains the clinical or radiological abnormality [20]. An important consideration in radiological-pathological correlation is whether classical lobular neoplasia is associated with calcification. The traditional view is that lobular neoplasia does not have a radiological correlate [4], but recent reports have described an association between classical lobular neoplasia and calcification. We also wished to investigate our impression that, in core biopsies containing classical lobular neoplasia, calcification is often associated with columnar cell change.

Pleomorphic LCIS is a recently described variant of lobular neoplasia. The growth pattern and absence of E-cadherin expression resemble classical LCIS. However, the marked nuclear pleomorphism, frequent presence of central necrosis and calcification and expression of c-erbB-2 are similar to high-grade DCIS [50]. In the past, pleomorphic LCIS would usually have been diagnosed as high-grade DCIS.

The main aim of this study was to assess the risk of invasive carcinoma and DCIS at the site of classical lobular neoplasia diagnosed on breast needle core biopsies. In view of the clear morphological differences, pleomorphic LCIS was considered separately. A second aim was to investigate the localisation of calcification in core biopsies containing lobular neoplasia.

\section{Materials and methods}

This project was discussed with the chair of the Nottingham University Hospitals Research Ethics Committee who considered that it was a service evaluation and, therefore, did not require formal ethical approval. A multidisciplinary review of the pathology and radiology of patients with a core biopsy diagnosis of lobular neoplasia from July 1998 to June 2006 was performed. The biopsies from July 1998 to June 2000 were included in a previous study [35]. The diagnosis of lobular neoplasia was made on haematoxylin and eosin sections. Immunohistochemistry for E-cadherin was performed for lesions with a differential diagnosis including DCIS or pleomorphic LCIS. Lobular neoplasia was subdivided into ALH and LCIS using the criteria described by Page et al. [44]. Pleomorphic LCIS was defined as a high-grade dyscohesive intra-acinar proliferation that was E-cadherin negative.

Patients were excluded if they had synchronous or previous invasive carcinoma or DCIS in the same breast. Two patients with contralateral invasive carcinoma were included. Core biopsies containing invasive carcinoma,
DCIS or an area suspicious of either diagnosis were excluded. Cores containing pleomorphic LCIS, an atypical intraductal epithelial proliferation (including atypical ductal hyperplasia), radial scar or a papillary lesion were considered separately. Thus, the main group of core biopsies studied contained classical lobular neoplasia with no other risk lesions: we termed this group "simple" classical lobular neoplasia.

The core biopsies were reviewed for the following features: location of any calcification and presence of columnar cell change. Six cores were not available, so could not be reviewed. The frequency of columnar cell change was compared with 87 consecutive core biopsies reported by one observer (AHSL) as normal or benign.

\section{Results}

Simple classical lobular neoplasia on core biopsy

Forty-nine core biopsies with lobular neoplasia from 47 women satisfied the entry criteria $(0.3 \%$ of the 14,597 diagnostic core biopsies performed during this period). Two patients had two core biopsies from the same area of the breast containing lobular neoplasia: both are only counted once in the following results. The median age was 52 years (range 33 to 81 ).

Twenty-six patients presented with mammographic screening abnormalities: 20 with calcification, 3 with a mass, 2 with calcification and distortion and 1 with a mass and calcification. Nineteen patients presented symptomatically: ten with a mass, seven with a thickening and two with a thickening and calcification. Two women had calcification identified by mammography performed in one patient as part of the investigation of a contralateral carcinoma and, in the other, as follow-up of a contralateral carcinoma. Eight core biopsies were freehand, 14 were ultrasound guided and 25 were performed under stereotactic guidance.

There was an association between lobular neoplasia and columnar cell change (see Table 1). Calcification was seen in 25 of 41 cores with slides available for review. It was seen in lobular neoplasia in six biopsies $(15 \%)$; in one the

Table 1 Extent of columnar cell change in cores with lobular neoplasia and controls

\begin{tabular}{lcc}
\hline $\begin{array}{l}\text { Columnar cell } \\
\text { change }\end{array}$ & $\begin{array}{l}\text { Core biopsy with } \\
\text { lobular neoplasia }\end{array}$ & $\begin{array}{c}\text { Controls (normal or } \\
\text { benign core biopsy) }\end{array}$ \\
\hline $\begin{array}{l}\text { None } \\
\text { One lobule or duct }\end{array}$ & $12(29 \%)$ & $58(67 \%)$ \\
$\begin{array}{l}\text { At least two lobules or } \\
\text { ducts }\end{array}$ & $20(22 \%)$ & $14(16 \%)$ \\
\hline
\end{tabular}

$\chi^{2}=18, P=0.0001$ 
calcification was only seen in the lobular neoplasia, but in the other five, it was also present in other changes (columnar cell change in three, sclerosing adenosis in one, fibroadenoma in one). Of the other 19 biopsies with calcification, columnar cell change was the most commonly associated pathology (10 biopsies).

Surgical excision within 2 months of core biopsy was performed in 25 patients. Excision showed malignancy in nine patients (see Table 2). In seven patients, pathologyradiology correlation showed that the core biopsy did not explain the radiological abnormality (a mass in five and calcification in two). Five of these seven patients were seen in the first 2 years of this study. Excision showed benign changes in 16, although one woman had invasive carcinoma of mixed ductal and lobular type diagnosed 33 months after the core biopsy in a separate quadrant of the same breast.

Nineteen patients who had not had a diagnostic surgical excision had follow-up of at least 2 years (range 25 to 105 months). None of these patients received radiotherapy to the breast. Malignancy was identified in seven women. In four, the malignancy was at the same site as the core biopsy (see Table 2), in one DCIS was found in a different quadrant of the same breast and two developed contralateral invasive carcinoma. Three women had no surgical excision and follow-up of less than 2 years. Neither of the two women with a previous history of contralateral invasive carcinoma developed carcinoma at the site of the core biopsy showing lobular neoplasia.

No significant relationships were found between the diagnosis of malignancy (DCIS, pleomorphic LCIS or invasive carcinoma) at the site of the core biopsy and the following features: age of the woman, diagnosis of ALH or LCIS on the core biopsy, whether core biopsy or vacuumassisted biopsy was performed and the method of guidance (freehand, ultrasound or stereotactic).

\section{Pleomorphic LCIS on core biopsy}

Both patients with pleomorphic LCIS on core biopsy presented with calcification detected by mammographic screening. In both, calcification was seen histologically in association with the pleomorphic LCIS. Both had a diagnostic surgical excision, which showed cribriform DCIS in one and further LCIS in the other.

\section{Atypical intraductal epithelial proliferation/radial scar/papillary lesion}

Eight patients had atypical intraductal epithelial proliferation, radial scar or a papillary lesion in addition to lobular neoplasia

Table 2 Details of patients with invasive carcinoma, DCIS or pleomorphic LCIS at the site of the core biopsy showing simple lobular neoplasia

\begin{tabular}{|c|c|c|c|c|c|}
\hline Age & Presentation & $\begin{array}{l}\text { Core } \\
\text { pathology }\end{array}$ & $\begin{array}{l}\text { Time to } \\
\text { excision/ } \\
\text { months }\end{array}$ & Final diagnosis (surgical procedure) & $\begin{array}{l}\text { Pathology-radiology } \\
\text { correlation }\end{array}$ \\
\hline 60 & Screen-detected mass & $\mathrm{ALH}, \mathrm{CCCh}$, calcs & 1 & 13 mm IDC, G3, LN 0/4 (Mx) & Core missed mass \\
\hline 75 & Symptomatic mass & LCIS, UEH, CCCh & 2 & 6 mm IDC, G2, LN not examined (Mx) & Core missed mass \\
\hline 63 & $\begin{array}{l}\text { Screen-detected distortion and } \\
\text { calcification. Mass on US }\end{array}$ & ALH & 1 & 14 mm ILC, G2, LN 0/5 (WLE) & Core missed mass \\
\hline 54 & Screen-detected calcification & ALH & 1 & $\begin{array}{l}4 \mathrm{~mm} \text { tubulobular carcinoma G1 + } \\
50 \mathrm{~mm} \text { DCIS, LN 0/6 }(\mathrm{Mx})\end{array}$ & Core missed calcs \\
\hline 43 & Symptomatic mass & LCIS & 1 & 9 mm IDLC, G2, LN 0/7 (Mx) & Core missed mass \\
\hline 68 & Screen-detected mass & ALH & 1 & 12 mm ILC, G2, LN 0/6 (Mx) & Core missed mass \\
\hline 64 & $\begin{array}{l}\text { Symptomatic mass, no mass on US. } \\
\text { Mammographic calcification }\end{array}$ & ALH, cyst, calcs & 1 & 7 mm DCIS (WLE) & Calcs sampled by core \\
\hline 54 & Screen-detected calcification & ALH & 1 & $\begin{array}{l}12 \mathrm{~mm} \text { tubular carcinoma }+35 \mathrm{~mm} \\
\text { DCIS, LN 0/4 (WLE) }\end{array}$ & Core missed calcs \\
\hline 45 & $\begin{array}{l}\text { Symptomatic cysts. Mammographic } \\
\text { calcification }\end{array}$ & LCIS, calcs & 1 & 5 mm pleomorphic LCIS (WLE) & Calcs sampled by core \\
\hline 52 & Screen-detected calcification & $\begin{array}{l}\mathrm{ALH}, \mathrm{UEH}, \\
\mathrm{CCCh}, \text { calcs }\end{array}$ & 31 & 9 mm ILC, G2, LN 1/6 (Mx) & $\begin{array}{l}\text { Mammographically } \\
\text { occult mass }\end{array}$ \\
\hline 70 & Screen-detected calcification & ALH, calcs & 29 & 36 mm IDC, G3, LN 6/16 (Mx) & $\begin{array}{l}\text { Dense original } \\
\text { mammogram }\end{array}$ \\
\hline 51 & Screen-detected calcification & $\mathrm{ALH}, \mathrm{CCCh}$, calcs & 26 & 30 mm DCIS + extensive LCIS (Mx) & Calcs sampled by core \\
\hline 55 & Screen-detected calcification & ALH, CCCh, calcs & 29 & IDC 8 mm, G3, 45 mm DCIS, LN 1/4 (Mx) & Calcs sampled by core \\
\hline
\end{tabular}

US ultrasound, ALH atypical lobular hyperplasia, LCIS lobular carcinoma in situ, UEH epithelial hyperplasia of usual type, CCCh columnar cell change, calcs calcification, IDC invasive ductal carcinoma, ILC invasive lobular carcinoma, IDLC invasive ductal and lobular carcinoma, DCIS ductal carcinoma in situ, $G$ histological grade, $L N$ axillary lymph nodes, $M x$ mastectomy, $W L E$ wide local excision 
on the core biopsy. All eight presented with abnormalities detected by mammographic screening: calcification in five, calcification and distortion in one, mass in one and distortion in one. Seven patients had a diagnostic surgical excision, and one patient had her lesion removed with vacuum-assisted mammotomy. DCIS was found in one of three women with core diagnosis of atypical intraductal epithelial atypia and in one of two with core diagnosis of radial scar. Papillary DCIS with a 3-mm focus of invasion was found after a core diagnosis of papillary lesion with atypical intraductal epithelial proliferation. One patient with a core diagnosis of radial scar with atypical intraductal epithelial proliferation and one with a papillary lesion had benign findings at excision.

\section{Discussion}

Relation between lobular neoplasia and calcification

An important question in the management of lobular neoplasia on core biopsy is the relationship between lobular neoplasia and calcification. Lobular neoplasia is not typically associated with any specific clinical abnormality, and there are no characteristic macroscopic features. Early papers suggested that classical lobular neoplasia does not have any diagnostic mammographic features [4]. In the past, surgical biopsies containing lobular neoplasia were frequently performed for mammographic calcification, but pathologically, the calcification was mostly associated with fibrocystic change and identified within the lobular neoplasia in about $20 \%[4,11,24,55]$. Calcification is associated with the lobular neoplasia in between $8 \%$ and $53 \%$ of core biopsies containing classical lobular neoplasia in different studies [1, 3, 14, 20, 41]. Benign calcification is frequently seen close to invasive carcinomas in surgical specimens [52]. It is well recognised that malignancy may be an incidental discovery on a biopsy for calcification that is associated only with benign disease [49].

The present study confirms the association between lobular neoplasia and columnar cell change $[8,41]$. In older studies, the majority of surgical biopsies containing lobular neoplasia were performed for fibrocystic change [30]. In the present study, calcification was associated with lobular neoplasia in $15 \%$ of core biopsies, but commonly was also seen in fibrocystic change as well. Calcification was associated with columnar cell change in $32 \%$ of cores with lobular neoplasia. The association of calcification with columnar cell change is well recognised [27]. Our results support the view that, in biopsies containing lobular neoplasia, most of the calcification is associated with fibrocystic change, particularly columnar cell change. Importantly, the lobular neoplasia is incidental to the calcification in the majority of biopsies.
A recent study of collagenous spherulosis found that 15 of 59 patients had associated LCIS [48]. In contrast, only one of the patients in the present study with lobular neoplasia had associated collagenous spherulosis.

Relationship between simple classical lobular neoplasia and carcinoma

In this study, 44 women with simple classical lobular neoplasia on core biopsy had surgical excision or follow-up of at least 2 years. Twenty-five women had immediate surgical excision, which showed invasive carcinoma, DCIS or pleomorphic LCIS in nine $(36 \%)$. In the majority, the core biopsy was judged to have missed the clinical/ radiological lesion. This emphasises the importance of clinico-pathological review and further investigation of any discordance. Most of the missed lesions occurred in the early part of the study, suggesting that the accuracy of radiological localisation of core biopsies may have improved later in the series. A smaller number of carcinomas occurred after lobular neoplasia on core biopsy apparently incidental to the clinical or radiological lesion. This raises the question of whether excision biopsy should be considered after all core biopsy diagnoses of lobular neoplasia. The frequency of malignancy if the patients with radiological-pathological discordance are excluded is $11 \%$ $(2 / 18)$.

Four of 19 patients with at least 2 years follow-up developed carcinoma at the site of the core biopsy. In one, the carcinoma was mammographically occult, although it was clinically palpable, in one the original mammogram was dense and two women had calcification apparently adequately sampled by the core biopsy. Definite comment cannot be made, but the clinical histories suggest that it is possible that the carcinoma may have been identified earlier in some of these patients if they had had an immediate surgical biopsy. If these women are added to those without radiological-pathological discordance in the above paragraph, the frequency of malignancy is $16 \%(6 / 37)$.

Previous published studies of simple lobular neoplasia on core biopsy were reviewed $[1-3,6,9,10,12,14,16-18$, $20,21,23,25,26,31,33,36,37,39,41-43,46,47,51,54$, $58,59]$. The data in most studies are not representative. Probably the major bias is that only about half of the lesions had a surgical biopsy and it is not clear how patients were selected for excision biopsy. Furthermore, most studies only report image-guided or stereotactic biopsies. A surgical biopsy was performed in 561 patients with a core biopsy diagnosis of lobular neoplasia with invasive carcinoma found in 50 or 49 and DCIS in 32 or 33 (82 [15\%] in total). It is 'impossible to know if some of the reported cases are those in which the targeted lesion has been missed and re-excision was done for failure to 
successfully sample the target' [15]. In reviewing the previous studies, we have assumed that sampling was adequate for core biopsy performed for calcification if calcification was present in the core biopsy. Of those 52 malignancies with details available, $25(48 \%)$ had a radiological-pathological discordance (missed mass in 22 and missed calcification in 3), and 27 had apparently adequately sampled calcification.

One hundred four patients who did not have immediate surgical excision had reported follow-up. The only four patients $(4 \%)$ with invasive carcinoma or DCIS on followup at the site of core biopsy are the four patients described in the present study. The absence of subsequent malignancy in other studies is very surprising given that lobular neoplasia is a well-established risk factor for later carcinoma. Nevertheless, the low rate suggests that the chance of invasive carcinoma or DCIS is lower in those not having immediate surgical excision.

It is difficult to estimate the chance of finding invasive carcinoma or DCIS if all patients had an excision biopsy. The $15 \%$ rate found in the subset of patients who had immediate excision biopsy is probably an overestimate. If the cases with radiological-pathological discordance are excluded, the risk is probably about half of this, approximately $8 \%$. If one assumes that half of the patients who did not have an immediate excision did not have invasive carcinoma or DCIS at the core site, this gives an estimate of about $4 \%$. This represents an estimate of the lower limit of risk.

Some studies suggest that the risk of finding invasive carcinoma or DCIS is a little higher if the core biopsy shows LCIS rather than ALH [13]. In view of the subjectivity of this distinction on core biopsy, it is probably of limited use in routine practice.

It is clearly appropriate to investigate patients with simple classical lobular neoplasia on core biopsy that does not explain the clinical or radiological abnormality. If a definitive diagnosis cannot be made with further core biopsy, then an excision biopsy is indicated.

The management of simple classical lobular neoplasia on core biopsy with no radiological-pathological discordance is less straightforward. As discussed above, the literature suggests that the risk of malignancy is in the range of $4 \%$ to $8 \%$. This risk is comparable to that associated with radial scar or papillary lesion with no epithelial atypia $[7,34,35$, $40,53]$. Both radial scars and papillary lesions are excised in many centres according to current guidance [19]. The major difference with lobular neoplasia, however, is that both are usually clearly defined lesions on radiological examination and therefore easy to excise.

There is a need for prospective studies with surgical excision of all lesions so that an unbiased assessment of the risk of simple classical lobular neoplasia on core biopsy can be made. Careful radiology-pathology correlation is essential.
It may be possible to stratify the risk within this group using clinical, radiological or pathological features.

Lobular neoplasia associated with radial scars, papillary lesions and atypical intraductal epithelial proliferations

Most centres excise radial scars, papillary lesions and atypical intraductal epithelial proliferations diagnosed on core biopsy. In the present study, carcinoma was found on excision of three of the eight lesions with these lesions in combination with lobular neoplasia. This supports the practice of excising such lesions.

\section{Pleomorphic LCIS}

In the present study, both cores with pleomorphic LCIS had associated calcification. In contrast to the controversial nature of the association between calcification and classical LCIS, the literature suggests that there is a clear relationship between calcification and pleomorphic LCIS $[29,50]$. There are limited data on the significance of pleomorphic LCIS on core biopsy. One of the two patients in the present study had DCIS in the excision specimen. Three of the six patients described in the literature [5, 20,37] had invasive carcinoma on excision, but radiology showed a density in one and an architectural distortion in another. Although the follow-up data are limited, we believe that, until there is further evidence, it is prudent to recommend that pleomorphic LCIS is managed as DCIS because of the morphological similarity of pleomorphic LCIS to high-grade DCIS. The present study may underestimate the frequency of pleomorphic LCIS, as E-cadherin immunohistochemistry was infrequently performed early in the study period and some cases may have been diagnosed as high-grade DCIS.

Some lobular neoplasia shows features overlapping with DCIS and is difficult to classify even with E-cadherin immunohistochemistry [32, 38]. Lobular neoplasia with comedo necrosis, but without marked nuclear pleomorphism, has recently been described [22]. The clinical significance of these rare clinico-pathological scenarios is uncertain. Until there is more evidence, it would be prudent to recommend surgical biopsy of such lesions because of the overlap of features with DCIS. Mass forming lobular neoplasia can occur rarely [56], but is an example of clinico-pathological discordance, so surgical biopsy is prudent.

In conclusion, we recommend excision after a core biopsy diagnosis of lobular neoplasia in the following circumstances:

1. Discordance of clinical or radiological findings with the pathological changes (this includes mass-forming lobular neoplasia) 
2. Lobular neoplasia with atypical histological features including pleomorphic LCIS, lobular neoplasia with necrosis, and when it is not possible to exclude DCIS despite E-cadherin immunohistochemistry

3. If there is an associated risk lesion, such as atypical intraductal epithelial proliferation, radial scar or papillary lesion.

We suggest that further studies are needed to guide the management of simple classical lobular neoplasia, as the data on the risk of associated carcinoma remain unclear in this group of patients.

Conflict of interest statement We declare that we have no conflict of interest.

\section{References}

1. Arpino G, Allred DC, Mohsin SK, Weiss HL, Conrow D, Elledge RM (2004) Lobular neoplasia on core-needle biopsy — clinical significance. Cancer 101:242-250

2. Bauer VP, Ditkoff BA, Schnabel F, Brenin D, El-Tamer M, Smith S (2003) The management of lobular neoplasia identified on percutaneous core breast biopsy. Breast J 9:4-9

3. Berg WA, Mrose HE, Ioffe OB (2001) Atypical lobular hyperplasia or lobular carcinoma in situ at core-needle breast biopsy. Radiology 218:503-509

4. Beute BJ, Kalisher L, Hutter RVP (1991) Lobular carcinoma in situ of the breast: clinical, pathologic, and mammographic features. AJR Am J Roentgenol 157:257-265

5. Bibeau F, Chateau MC, Masson B (2003) Prise en charge des lésions mammaires infra-cliniques par macrobiopsies assistées par le vide (procédure Mammotome). Expérience du Centre Val d'Aurelle à propos d'une série de 560 procédures. [Management of non-palpable breast lesions with vacuum-assisted large core needle biopsies (Mammotome). Experience with 560 procedures at the Val d'Aurelle Center]. Ann Pathol 23:582-592

6. Bonnett M, Wallis T, Rossmann M, Pernick NL, Bouwman D, Carolin KA, Visscher D (2003) Histopathologic analysis of atypical lesions in image-guided core breast biopsies. Mod Pathol 16:154-160

7. Brenner RJ, Jackman RJ, Parker SH, Evans WP, Philpotts L, Deutch BM, Lechner MC, Lehrer D, Sylvan P, Hunt R, Adler SJ, Forcier N (2002) Percutaneous core needle biopsy of radial scars of the breast: when is excision necessary. AJR Am J Roentgenol 179:1179-1784

8. Brogi E, Oyama T, Koerner FC (2001) Atypical cystic lobules in patients with lobular neoplasia. Int J Surg Pathol 9:201-206

9. Burak WE, Owens KE, Tighe MB, Kemp L, Dinges SA, Hitchcock CL, Olsen J (2000) Vacuum-assisted stereotactic breast biopsy: histologic underestimation of malignant lesions. Arch Surg 135:700-703

10. Cangiarella J, Waisman J, Symmans WF, Gross J, Cohen JM, Wu H, Axelrod D (2001) Mammotome core biopsy for mammary microcalcification: analysis of 160 biopsies from 142 women with surgical and radiologic followup. Cancer 91:173-177

11. Carson W, Sanchez-Forgach E, Stomper P, Penetrante R, Tsangaris TN, Edge SB (1994) Lobular carcinoma in situ: observation without surgery as an appropriate therapy. Ann Surg Oncol 1:141-146

12. Cassano E, Urban LABD, Pizzamiglio M, Abbate F, Maisonneuve P, Renne G, Viale G, Bellomi M (2007) Ultrasound-guided vacuumassisted core breast biopsy: experience with 406 cases. Breast Cancer Res Treat 102:103-110

13. Cohen MA (2004) Cancer upgrades at excisional biopsy after diagnosis of atypical lobular hyperplasia or lobular carcinoma in situ at core-needle biopsy: some reasons why. Radiology 231:617-621

14. Crisi GM, Mandavilli S, Cronin E, Ricci A (2003) Invasive mammary carcinoma after immediate and short-term follow-up for lobular neoplasia on core biopsy. Am J Surg Pathol 27:325-333

15. Dershaw DD (2003) Does LCIS or ALH without other high-risk lesions diagnosed on core biopsy require surgical excision. Breast J 9:1-3

16. Diebold T, Hahn T, Solbach C, Rody A, Balzer JO, Hansmann ML, Marx A, Viana F, Peters J, Jacobi V, Kaufmann M, Vogl TJ (2005) Evaluation of the stereotactic $8 \mathrm{G}$ vacuum-assisted breast biopsy in the histologic evaluation of suspicious mammography findings (BIRADS IV). Invest Radiol 40:465-471

17. Dillon MF, McDermott EW, Hill AD, O'Doherty A, O'Higgins N, Quinn CM (2007) Predictive value of breast lesions of "uncertain malignant potential" and "suspicious of malignancy" determined by needle core biopsy. Ann Surg Oncol 14:704-711

18. Dmytrasz K, Tartter PI, Mizrachy H, Chinitz L, Rosenbaum Smith S, Estabrook A (2003) The significance of atypical lobular hyperplasia at percutaneous breast biopsy. Breast J 9:10-12

19. Ellis IO, Humphreys S, Michell M, Pinder SE, Wells CA, Zakhour HD (2004) Best Practice No 179. Guidelines for breast needle core biopsy handling and reporting in breast screening assessment. J Clin Pathol 57:897-902

20. Elsheikh TM, Silverman JF (2005) Follow-up surgical excision is indicated when breast core needle biopsies show atypical lobular hyperplasia or lobular carcinoma in situ: a correlative study of 33 patients with review of the literature. Am J Surg Pathol 29:534-543

21. Esserman LE, Lamea L, Tanev S, Poppiti R (2007) Should the extent of lobular neoplasia on core biopsy influence the decision for excision. Breast J 13:55-61

22. Fadare O, Dadmanesh F, Alvarado-Cabrero I, Snyder R, Mitchell JS, Tot T, Wang SA, Ghofrani M, Eusebi V, Martel M, Tavassoli FA (2006) Lobular intraepithelial neoplasia [lobular carcinoma in situ] with comedo-type necrosis: A clinicopathologic study of 18 cases. Am J Surg Pathol 30:1445-1453

23. Fajardo LL, Pisano ED, Caudry DJ, Gatsonis CA, Berg WA, Connolly J, Schnitt S, Page DL, McNeil BJ (2004) Stereotactic and sonographic large-core biopsy of nonpalpable breast lesions: results of the Radiologic Diagnostic Oncology Group V study. Acad Radiol 11:293-308

24. Fisher ER, Costantino J, Fisher B, Palekar AS, Paik SM, Suarez CM, Wolmark N (1996) Pathologic findings from the National Surgical Adjuvant Breast Project (NSABP) Protocol B-17. Five-year observations concerning lobular carcinoma in situ. Cancer 78:1403-1416

25. Foote FW, Stewart FW (1941) Lobular carcinoma in situ: a rare form of mammary cancer. Am J Pathol 17:491-496

26. Foster MC, Helvie MA, Gregory NE, Rebner M, Nees AV, Paramagul C (2004) Lobular carcinoma in situ or atypical lobular hyperplasia at core-needle biopsy: is excisional biopsy necessary. Radiology 231:813-819

27. Fraser JL, Raza S, Chorny K, Connolly JL, Schnitt SJ (1998) Columnar alteration with prominent apical snouts and secretions: a spectrum of changes frequently present in breast biopsies performed for microcalcifications. Am J Surg Pathol 22:15211527

28. Fulford LG, Reis-Filho JS, Lakhani SR (2004) Lobular in situ neoplasia. Curr Diagn Pathol 10:183-192 
29. Georgian-Smith D, Lawton TJ (2001) Calcifications of lobular carcinoma in situ of the breast: radiologic-pathologic correlation. AJR Am J Roentgenol 176:1255-1259

30. Haagenson CD, Lane N, Lattes R, Bodian C (1978) Lobular neoplasia (so-called lobular carcinoma in situ) of the breast. Cancer 42:737-769

31. Irfan K, Brem RF (2002) Surgical and mammographic follow-up of papillary lesions and atypical lobular hyperplasia diagnosed with stereotactic vacuum-assisted biopsy. Breast J 8:230-233

32. Jacobs TW, Pliss N, Kouria G, Schnitt SJ (2001) Carcinoma in situ of the breast with indeterminate features: role of E-cadherin staining in categorisation. Am J Surg Pathol 25:229-236

33. Karabakhtsian RG, Johnson R, Sumkin J, Dabbs DJ (2007) The clinical significance of lobular neoplasia on breast core biopsy. Am J Surg Pathol 31:717-723

34. Kirwan SE, Denton ERE, Nash RM, Humphreys S, Michell MJ (2000) Multiple 14G stereotactic core biopsies in the diagnosis of mammographically detected stellate lesions of the breast. Clin Radiol 55:763-766

35. Lee AHS, Denley HE, Pinder SE, Ellis IO, Elston CW, Vujovic P, Macmillan RD, Evans AJ (2003) Excision biopsy findings of patients with breast needle core biopsies reported as suspicious of malignancy (B4) or lesion of uncertain malignant potential (B3). Histopathology 42:331-336

36. Liberman L, Sama M, Susnik B, Rosen PP, La Trenta LR, Morris EA, Abramson AF, Dershaw DD (1999) Lobular carcinoma in situ at percutaneous breast biopsy: surgical biopsy findings. Am J Roentgenol 173:291-299

37. Mahoney MC, Robinson-Smith TM, Shaughnessy EA (2006) Lobular neoplasia at 11-gauge vacuum-assisted stereotactic biopsy: correlation with surgical excisional biopsy and mammographic follow-up. AJR Am J Roentgenol 187:949-954

38. Maluf HM, Swanson PE, Koerner FC (2001) Solid low-grade in situ carcinoma of the breast: role of associated lesions and Ecadherin in differential diagnosis. Am J Surg Pathol 25:237-244

39. Margenthaler JA, Duke D, Monsees BS, Barton PT, Clark C, Dietz JR (2006) Correlation between core biopsy and excisional biopsy in breast high-risk lesions. Am J Surg 192:534-537

40. Mercado CL, Hamele-Bena D, Oken SM, Singer CI, Cangiarella J (2006) Papillary lesions of the breast at percutaneous core-needle biopsy. Radiology 238:801-808

41. Middleton LP, Grant S, Stephens T, Stelling CB, Sneige N, Sahin AA (2003) Lobular carcinoma in situ diagnosed by core needle biopsy: when should it be excised. Mod Pathol 16:120-129

42. O'Driscoll D, Britton P, Bobrow L, Wishart GC, Sinnatamby R, Warren R (2001) Lobular carcinoma in situ on core biopsy-what is the clinical significance. Clin Radiol 56:216-220

43. Orel SG, Rosen M, Mies C, Schnall MD (2006) MR imagingguided 9-gauge vacuum-assisted core-needle breast biopsy: initial experience. Radiology 238:54-61

44. Page DL, Kidd TE, Dupont WD, Simpson JF, Rogers LW (1991) Lobular neoplasia of the breast: higher risk for subsequent invasive cancer predicted by more extensive disease. Hum Pathol 22:1232-1239
45. Page DL, Schuyler PA, Dupont WD, Jensen RA, Plummer WD, Simpson JF (2003) Atypical lobular hyperplasia as a unilateral predictor of breast cancer risk: a retrospective cohort study. [erratum in Lancet. 2003;361:1994]. Lancet 361:125-129

46. Philpotts LE, Shaheen NA, Jain KS, Carter D, Lee CH (2000) Uncommon high-risk lesions of the breast diagnosed at stereotactic core-needle biopsy: clinical importance. Radiology 216:831-837

47. Renshaw AA, Cartagena N, Derhagopian RP, Gould EW (2002) Lobular neoplasia in breast core needle biopsy specimens is not associated with an increased risk of ductal carcinoma in situ or invasive carcinoma. Am J Clin Pathol 117:797-799

48. Resetkova E, Albarracin C, Sneige N (2006) Collagenous spherulosis of breast: morphologic study of 59 cases and review of the literature. Am J Surg Pathol 30:20-27

49. Rosenfeld I, Tartter PI, Gajdos C, Hermann G, Bleiweiss I (2001) The significance of malignancies incidental to microcalcifications in breast spot localization biopsy specimens. Am J Surg 182:1-5

50. Sapino A, Frigerio A, Peterse JL, Arisio R, Coluccia C, Bussolati G (2000) Mammographically detected in situ lobular carcinomas of the breast. Virchows Arch 436:421-430

51. Sauer G, Deissler H, Strunz K, Helms G, Remmel E, Koretz K, Terinde R, Kreienberg R (2005) Ultrasound-guided large-core needle biopsies of breast lesions: analysis of 962 cases to determine the number of samples for reliable tumour classification. Br J Cancer 92:231-235

52. Selim A, Tahan SR (1998) Microscopic localization of calcifications in and around breast carcinoma: a cautionary note for needle core biopsies. Ann Surg 228:95-98

53. Shah VI, Flowers CI, Douglas-Jones AG, Dallimore NS, Rashid M (2006) Immunohistochemistry increases the accuracy of diagnosis of benign papillary lesions in breast needle core biopsy specimens. Histopathology 48:683-691

54. Shin SJ, Rosen PP (2002) Excisional biopsy should be performed if lobular carcinoma in situ is seen on needle core biopsy. Arch Pathol Lab Med 126:697-701

55. Sonnenfeld MR, Frenna TH, Weidner N, Meyer JE (1991) Lobular carcinoma in situ: mammographic-pathologic correlation of results of needle-directed biopsy. Radiology 181:363-367

56. Stein LF, Zisman G, Rapelyea JA, Schwartz AM, Abell B, Brem RF (2005) Lobular carcinoma in situ of the breast presenting as a mass. AJR Am J Roentgenol 184:1799-1801

57. Vos CBJ, Cleton-Jansen AM, Berx G, de Leeuw WJF, ter Haar NT, van Roy F, Cornelisse CJ, Peterse JL, van de Vijver MJ (1997) E-cadherin inactivation in lobular carcinoma in situ of the breast: an early event in tumorigenesis. Br J Cancer 76:1131-1133

58. Yeh IT, Dimitrov D, Otto P, Miller AR, Kahlenberg MS, Cruz A (2003) Pathologic review of atypical hyperplasia identified by image-guided breast needle core biopsy. Correlation with excision specimen. Arch Pathol Lab Med 127:49-54

59. Zuiani C, Londero V, Bestagno A, Puglisi F, Di Loreto C, Bazzocchi M (2005) Proliferative high-risk lesions of the breast: contribution and limits of US-guided core biopsy. Radiol Med 110:589-602 